\title{
Estandarización cultural y marginalidad lingüística. El siglo XVII: una gran paradoja en la historia de la lengua española
}

\section{Cultural Standardization and Linguistic Marginality. The Seventeenth Cen- tury: a Great Paradox in the History of the Spanish Language}

CONCEPCIÓN COMPANY COMPANY [company@unam.mx]

Universidad Nacional Autónoma de México, México

\section{RESUMEN}

Este trabajo analiza el particular comportamiento sintáctico del siglo XVII, y sus resultados no solo ponen en cuestionamiento algunas de las propiedades del cambio lingüístico, sino que también arrojan nueva luz sobre el lugar peculiar o especial de esta centuria en la periodización del español. El objetivo general es, por tanto, analizar la peculiaridad lingüística del siglo XVII en una diacronía amplia del español, así como mostrar que un diálogo interdisciplinario entre la lengua, la literatura, la historia y los estudios culturales proporciona un mejor entendimiento de su peculiar complejidad sintáctica.

\section{PALABRAS CLAVE}

Siglo XVII; sintaxis histórica; periodización; cambio lingüístico

\begin{abstract}
This paper analyzes the specific syntactic behavior of the Spanish language during the seventeenth century. The results of this study not only put into question some of the assumed properties of linguistic change, but also shed new light on the key role of this century in the periodization of Spanish. Therefore, our general objective is to analyze the linguistic peculiarities of the seventeenth century in a broad diachrony of Spanish. In addition, we suggest that an interdisciplinary dialogue between language, literature, history, and cultural studies is essential in order to provide a better understanding of syntactic complexity during this time period.
\end{abstract}

\section{KEYWORDS}

17th century; historical syntax; periodization; linguistic change

RECIBIDO 2018-03-21; ACEPTADO 2018-05-18

Este trabajo apareció inicialmente publicado en Hispanismos del mundo. Diálogos y debates en ( $y$ desde) el Sur. (Actas del XVIII Congreso Internacional de la Asociación Internacional de Hispanistas, Buenos Aires, 15-20 de julio de 2013), L. Funes (ed.), Buenos Aires: Miño y Dávila Editores, 2016, pp. 131-158. Agradezco el permiso de reproducción. 


\section{Introducción. El siglo XVII, un periodo privilegiado}

El lugar privilegiado del siglo XVII en la historia de la lengua española y en la cultura en esta lengua está fuera de toda duda. En efecto, un aspecto recurrente, y bien conocido, de todas las gramáticas históricas internas del español y de las historias externas de la lengua española, y, en lo general, de todo tipo de obras que nos acerquen a la historia de la cultura y de la sociedad en lengua española es que el siglo XVII constituye un periodo de especial relevancia, en lo cultural, en lo literario y en lo lingüístico. Sea que el análisis se haga con un enfoque más lingüístico, sea que se haga con uno más literario, sea que se realice con uno más sociocultural o con uno histórico en general, en todos, el siglo XVII goza de un particular privilegio. Tal lugar privilegiado es tanto cualitativo como cuantitativo.

En perspectiva cualitativa, el siglo XVII dicta las periodizaciones de nuestra lengua, sean estas bipartitas o tripartitas. Así, la ya clásica división bipartita del español en "antiguo y moderno", tiene como eje y protagonista simbólico de esa clasificación el año 1600 (Menéndez Pidal 1940, 1991); o, sin un año preciso, la centuria del XVII establece una referencia divisoria por sí misma (Eberenz 1991). En las divisiones tripartitas, el siglo XVII constituye un periodo propio; en efecto, en las cronologías de nuestra lengua que dividen el español en "medieval, moderno y contemporáneo" (Lapesa 1981), el siglo XVII es el español moderno, mientras que los siglos precedente y subsecuente ocupan un lugar variable y a veces poco claro: el XVI suele ser considerado el umbral del español moderno y, por su parte, el siglo XVIII, aunque es clasificado como moderno, constituye una modernidad desatendida, una mera continuidad lingüística respecto del siglo precedente, que, hasta hace muy poco, constituía un verdadero vacío de conocimiento para la historia del español.

Desde otro ángulo de análisis, el siglo XVII, como se sabe, ha sido calificado una y otra vez como el "siglo de oro", escrito casi siempre en mayúsculas, "Siglo de Oro", graficación que equipara el siglo XVII a un nombre propio, con un referente único y exclusivo, mientras que el siglo XVI a veces se une a este calificativo de aúreo, y se habla de los "siglos de oro" o de los "Siglos de Oro", pero a veces queda excluido. Además, con no poca frecuencia los especialistas en literatura de este periodo hablan indistintamente y en un mismo trabajo de Siglos de Oro y de Siglo de Oro, y también con cierta frecuencia empiezan tratando ambos siglos como áureos, en plural por tanto, y terminan por concentrar su atención en el XVII ${ }^{1}$, señal de que este siglo, y no el anterior, es, sin duda alguna, el áureo para la lengua y la literatura españolas. En los apartados que siguen, veremos que el siglo XVI tiene un comportamiento sintáctico bastante diferente del XVII y que, por ello, es conveniente tratarlos por separado, al menos en lo que a la lingüística concierne.

También es común calificar la lengua del siglo XVII como "español clásico" — una lengua modélica, debemos entender-, mientras que los siglos precedente y subsecuente quedan excluidos de esta clasificación: el XVI es etiquetado como "preclásico" y el XVIII no suele recibir

1 Cf., entre otros muchos estudiosos, el trabajo de Montaner (1989), paradigmático, en mi opinión, de este desplazamiento cronológico en el objetivo del trabajo, sin comentario o aviso alguno por parte del crítico literario; asimismo algunos de los trabajos contenidos en el número monográfico de la revista Edad de Oro, volumen 7, correspondiente al año 1988, que son los que sustentan y dan pie al artículo antecitado de Montaner; tal desplazamiento cronológico es también común en historias de la literatura. 
calificación alguna a este respecto, aunque sin duda queda fuera de esta naturaleza clásica y modélica. El siglo XVII ha sido también considerado con mucha frecuencia como el periodo de mayor esplendor general, cultural, literario y lingüístico de la cultura en lengua española (Abad 2004), como un periodo de "revolución" fonológica (Ariza 1994), como el periodo que despliega la mayor concentración de cambios del español (Girón Alconchel 2004) y como un periodo extraordinario y peculiar desde el punto de vista sociolingüístico y psicolingüístico, ya que, al parecer, existía una conciencia lingüística y cultural bastante desarrollada, y no sólo en quienes podrían ser llamados los intelectuales del momento sino en el pueblo llano inclusive (Gauger 2004).

La opinión de López Grigera (2004: 707) resume bien, a mi modo de ver, el sentir generalizado y perspectiva de muchos estudiosos sobre la unicidad y relevancia del siglo XVII: "Los textos literarios de la época de los Austrias constituyen, sin ninguna duda, la mayor riqueza de nuestra lengua". Y, en general, la apreciación histórica lingüística es que desde el siglo XVII "las grandes líneas de la estructura idiomática no han variado [...] Ni en el plano fónico, ni en el morfosintáctico puede señalarse en este periodo [siglo XVIII] ninguna alteración fundamental" (Cano 1988: 255).

En perspectiva cuantitativa, el siglo XVII goza también de un lugar privilegiado desde los inicios de la gramática histórica española por la cantidad de estudios y páginas a él dedicados. De hecho, es el causante de una desproporción numérica fuerte en las gramáticas e historias de nuestra lengua. Basten cuatro ejemplos. La obra ya clásica de Lapesa (1981), Historia de la lengua española, contiene, en tres capítulos, 127 páginas dedicadas al siglo XVII, de un total de 590 de análisis y exposición de datos, lo cual significa que un solo siglo supone casi $22 \%$ de la obra total, esto es, un siglo ocupa casi la cuarta parte de la atención en una obra de carácter abarcador y general, intitulada por ello Historia de la lengua española. Por su parte, la obra colectiva Historia de la lengua española, coordinada por Cano (2004), mantiene proporciones semejantes: 256 páginas dedicadas al siglo XVII, de un total de 1132, lo cual representa casi el 23\% del total del libro; es decir, un sólo siglo vuelve a merecer casi la cuarta parte de una obra que analiza un devenir de veinte siglos de historia del español, puesto que empieza con los antecedentes latinos y con las lenguas prerromanas de sustrato y llega para algunos temas al siglo XX. La recientemente publicada obra de Menéndez Pidal, Historia de la lengua española (2005), refleja proporciones similares para el análisis del siglo XVII: dedica seis capítulos, que suman 271 páginas, a este siglo, lo cual representa casi $21 \%$ de las 1337 páginas de este libro. En resumen, un solo siglo concentra, una y otra vez, casi la cuarta parte de información de la historia de la lengua española. Asimismo, con base en datos cuantitativos sobre el orden de constituyentes en la oración en la diacronía del español, Aguilar, Aguilar, Araiza y Melis (2006) han propuesto, como lo hicieran otros autores antes con base en otros fenómenos de lengua, que el siglo XVII en sí mismo constituye un "tercer periodo evolutivo del español”.

En suma, el lugar privilegiado del siglo XVII en la historia de nuestra lengua está fuera de toda duda. Sea en perspectiva cualitativa, sea en perspectiva cuantitativa, sea en sincronía, sea en diacronía, el siglo XVII, él solo, es un pilar sobre el que se ha construido la historia del español. Es, sin lugar a duda, un parteaguas en todos los acercamientos y desde todos los puntos de vista: antes del XVII, después del XVII o en el siglo XVII. Tal privilegio es bastante lógico porque la gramática histórica está en gran medida subordinada a la lengua escrita, particular- 
mente la literaria, en cuanto que existe mucha más documentación de esta que de otros tipos de textos escritos - jurídicos, notariales y periodísticos, por ejemplo- y porque, en esencia, nunca sabremos cómo era la lengua oral de estados pretéritos de nuestra lengua. Lo que es menos lógico es que la gramática histórica se subordine a las grandes obras literarias, subordinación esta última sobre la que, a mi modo de ver, se sustentan, en buena parte, las apreciaciones de "áureo", "clásico", "de esplendor", etc., recurrentes para esa centuria.

Este trabajo, además de esta introducción, está estructurado en cinco apartados. En $\$ 2$ expongo el problema de investigación que plantea el siglo XVII para la sintaxis histórica y establezco los objetivos. En el apartado $\$ 3$ esbozo de manera muy resumida la caracterización de algunas de las propiedades comúnmente aceptadas del cambio sintáctico. El apartado $₫ 4$ consiste en la exposición del corpus que constituye la base del análisis y el tratamiento de los datos lingǘsticos, cuyo resultado, como veremos, pone en cuestionamiento algunas de las propiedades del cambio lingüístico y arrojan nueva luz sobre el lugar peculiar o especial del siglo XVII en la periodización del español; ocasionalmente algún cambio aparece respaldado con ejemplos de la prosa del XVII, a manera de correlato cualitativo de los datos estadísticos expuestos; por razones de espacio no es posible mostrar los correlatos cualitativos de cada uno de los cambios en la prosa del XVII. El apartado $\$ 5$ es una interpretación interdisciplinaria del particular comportamiento sintáctico del siglo XVII, que intenta poner en diálogo la lengua con la literatura, con la sociología y con la historia, diálogo que espero arroje alguna luz a la peculiaridad gramatical de esa centuria. Cierran unas conclusiones en $\$ 6$, tanto lingüísticas como derivadas del acercamiento interdisciplinario de este trabajo.

\section{El problema de investigación y objetivos}

La adecuada caracterización lingüística del siglo XVII es un verdadero reto para la teoría del cambio sintáctico porque esta centuria se sustrae una y otra vez, y en muchas y distintas zonas de la gramática, a varios de los postulados del cambio, tales como su gradualidad y lentitud, su naturaleza continua y su carácter estratificado, conocido también como acumulación, de manera que el resultado general en el conjunto de siglos que forman la diacronía del español es que el XVII es un periodo lingüísticamente "raro".

En efecto, cuando es posible observar diacronías amplias y comparar el siglo XVII con los periodos precedentes y subsecuentes, se ve que este siglo realiza dos tipos de cambio un tanto contradictorios entre sí, ambos con un efecto estadístico brusco. Por un lado, es un siglo de una gran generalización de formas y construcciones y es el siglo de la estandarización de un número muy importante de cambios, las cuales producen la idea de que el XVII es un periodo - posiblemente el periodo- en que la sintaxis se vuelve moderna, en el sentido de que muchas estructuras sintácticas adquieren la caracterización con que llegan hasta el español actual. Por otro lado, sin embargo, es un periodo de fuertes quiebres manifestados en forma de una gran retracción, de una fuerte desproporción de las dinámicas usuales del cambio sintáctico, al punto de que los datos del extenso corpus diacrónico analizado — consignado más adelante en $\$ 4-$ muestran que para un número nada desdeñable de cambios existe mucha más afinidad sintáctica entre los siglos XVI y XVIII que entre cada uno de ellos y el siglo XVII, motivo por el 
cual es inadecuado en sintaxis histórica hablar de Siglos de Oro, en plural, uniendo el XVI con el XVII. Adelantemos, además, que es en la segunda mitad del siglo XVII, sobre todo a partir de 1640, cuando se manifiestan de manera más contundente las dinámicas de cambio aquí esbozadas, si bien casi toda la centuria tiene una actividad lingüística especial en el conjunto de la diacronía del español.

Estandarización más retracción otorgan al siglo XVII la apariencia de una gran paradoja. La paradoja es aún más llamativa o sorprendente porque lo esperado para este siglo sería que hubiera una esencial continuidad lingüística, continuidad derivada tanto de la dinámica usual del cambio lingüístico, que se manifiesta más como continuidad que como discontinuidad, cuanto, sobre todo, derivada de la gran estandarización de la lengua española que tuvo lugar a fines del siglo XV e inicios del XVI con motivo de la enorme difusión de la imprenta promovida por los Reyes Católicos. Esto es, aunque el paso de la cultura manuscrita a la cultura impresa fue un hecho gradual y no necesariamente lineal en el modo de sustitución de una por otra, se sabe que en el periodo de los Reyes Católicos se dio un gran espaldarazo oficial a la literatura y a la cultura impresas (Tejedo-Herrero 2012: 424-425 y referencias ahí citadas), y esa fuerte difusión de la imprenta genera una expectativa en cuanto a la dinámica de los cambios sintácticos, a saber, que estos se hagan más lentos porque la imprenta produce un efecto lingüístico generalizador y estandarizador y, produce por tanto, un enlentecimiento de los cambios, y porque, cosa sabida, la intervención de los impresores puede, y suele, hasta la fecha, tener un efecto de fijación de modelos de escritura, de manera que ambos hechos — difusión de textos impresos más intervención de impresores- enlentecen las dinámicas del cambio lingüístico.

En suma, el problema de investigación que aflora en este trabajo es que la esperada continuidad y gradualidad del cambio sintáctico se rompe en el siglo XVII en un número nada desdeñable de cambios sintácticos producidos en muy diversas zonas gramaticales no relacionadas entre sí. La ausencia de relacionalidad gramatical entre los fenómenos otorga, en mi opinión, más peso a la paradoja aquí planteada. El efecto general que produce el siglo XVII es que, además de paradójico o contradictorio, constituye un periodo que pone en tela de juicio el comportamiento prototípico esperado del cambio sintáctico, al punto de que, en términos estadísticos, como veremos, puede ser calificado de un outlier - un "desvirtuador", a falta de una mejor traducción - para la periodización sintáctica del español, ya que la línea evolutiva de bastantes cambios exhibe en el siglo XVII un quiebre o inflexión muy brusca y un tanto anómala. El calificativo de outlier no tiene en este trabajo valoración negativa alguna, simplemente significa que ese siglo, como ningún otro siglo en la historia sintáctica, rompe la gradualidad y continuidad del cambio sintáctico y constituye, respecto de otros periodos, un momento especial en la diacronía de la lengua española, motivo por el cual requiere de una mirada particular y detenida.

Sin duda, a pesar de la paradoja y de la puesta en tela de juicio de los postulados teóricos que el siglo XVII provoca, “algo" tendrá este siglo que tanta y tanta atención ha merecido y sigue requiriendo en la historia del español. Adentrarnos en esas peculiaridades e intentar explicarlas, así sea parcialmente, es el objetivo de este trabajo.

El objetivo general es, por tanto, analizar la peculiaridad lingüística del siglo XVII en una diacronía amplia del español. Un objetivo complementario para lograr este primer objetivo es mostrar que un diálogo interdisciplinario entre la lengua, la literatura, la historia y los estudios 
culturales proporciona un mejor entendimiento de la peculiar complejidad sintáctica del siglo XVII. Una propuesta de este trabajo es, en consecuencia, que un regreso a la filología tradicional, como una disciplina interdisciplinaria, pero con una nueva mirada y con renovadas herramientas de análisis, puede enriquecer la comprensión tanto de la lengua como de las manifestaciones culturales que en ella se soportan.

\section{Los procesos "normales" del cambio sintáctico}

Un postulado bien conocido del cambio gramatical es que este es continuidad + discontinuidad y ambas tendencias operan de manera conjunta, simultánea, nunca equilibrada en la manifestación de cualquier lengua en cualquier etapa. El cambio gramatical es tanto evolución como preservación de la estructura (Bybee 2010: cap. 1; Company 2012, 2015). En esencia, un cambio lingüístico, puede ser definido como una discontinuidad observable puesto que la lengua opera como una constante transformación imperceptible que se inserta en la gran continuidad que constituye el fundamento de toda lengua y que es su esencia misma.

La discontinuidad debe ser entendida como un conjunto de pequeños microquiebres, cada uno de los cuales en sí mismo no es observable aunque el sistema lingüístico los incorpora y opera con ellos constantemente. Cuando se suman varios de esos microquiebres se produce una catástrofe elemental, en el sentido de la teoría de las catástrofes de René Thom (1983), definida como una discontinuidad observable, cuya consecuencia es que se reequilibran las relaciones en el interior del sistema lingüístico, se ajusta la comunicación y, gracias a ello, la lengua sigue funcionando. Un microquiebre sintáctico no es obervable porque los hablantes lo producen de manera inconsciente, ya que, en realidad, la esencia del cambio, como se ha dicho numerosas veces, es que nadie quiere cambiar nada, motivo por el cual hay mucha más continuidad que discontinuidad en el devenir de cualquier lengua. Se requiere, como digo, de varios microquiebres acumulados para que se produzca un cambio o discontinuidad obervable. El siglo XVII concentra y conjunta en su sintaxis un elevado número de microquiebres, al punto de que, como veremos, él solo parece constituir una catástrofe elemental de la diacronía.

En condiciones normales de la evolución interna de una lengua, un cambio sintáctico o discontinuidad observable se caracteriza por, al menos, cuatro propiedades básicas: $a$ ) ser un proceso inferencial y dependiente del contexto, $b$ ) ser un proceso gradual, $c$ ) ser un proceso lentísimo, $\mathrm{y} d$ ) ser un proceso estratificado o acumulativo. El comportamiento lingüístico de muchos fenómenos en el siglo XVII, como veremos, constituye un serio cuestionamiento de las propiedades b) y c) del cambio.

El cambio sintáctico y la sintaxis, en general, a diferencia de la fonología o la morfología, tienen además la propiedad de ser siempre parafraseables, en el sentido de que siempre hay material sintáctico similar que puede llenar el espacio funcional en cuestión, en caso de un vacío sintáctico; ello evita que se produzcan vacíos comunicativos que suspendan la comunicación entre dos seres humanos; y, en efecto, jamás en comunidad lingüística alguna se ha producido un impedimento de comunicación por carencia de material sintáctico. Es decir, en sintaxis, a diferencia de en fonología o en morfología, no existe el cero sintáctico. 
a) Proceso inferencial. Es un proceso inferencial y dependiente del contexto porque las formas no cambian solas de manera aislada sino en distribuciones y contextos específicos, que son altamente favorables o afines a la forma, construcción o significado innovadores que está entrando en proceso de cambio y que compite con la forma, la construcción o el significado conservadores. Esa dependencia del contexto motiva que sea un proceso inferencial en el sentido de que el oyente carga la forma o construcción en cuestión con nuevos matices semánticos que no son parte integrante de la forma sino que están inferidos, extraídos, del contexto, lingüístico e incluso extralingüístico. Cuando el oyente toma el turno de hablante, emplea la forma o construcción enriquecida con nuevos matices y la usa en nuevas distribuciones, comparte o socializa el significado extraído por inferencia, y con el tiempo ese nuevo significado termina por convencionalizarse. Un mecanismo fundamental de este proceso inferencial es la elisión de formas o incluso de tramos completos del contexto lingüístico, ya que a medida que se convencionaliza la inferencia, tal convencionalización hace posible prescindir del contexto originario motivador de dicha inferencia.

b) Proceso gradual. En general se acepta que el cambio sintáctico-semántico es gradual en el sentido de que las transiciones entre las distintas fases del cambio gramatical se producen de manera imperceptible. Las causas de la gradualidad parecen obvias: por un lado, nadie quiere, voluntariamente, cambiar nada en la gramática y, por otro, el contexto y la fase previa del cambio condicionan y limitan enormemente la progresión del cambio y generan ajustes y reajustes mínimos y constantes que impiden discontinuidades abruptas.

c) Proceso lentísimo. Un requisito del cambio lingüístico es preservar la comunicación entre generaciones. Por ello, el cambio procede a manera de mínimos e imperceptibles desajustes que, junto con la gradualidad, hacen que la progresión de un cambio tarde siglos en convencionalizarse en una comunidad y tarde todavía más tiempo en manifestarse de manera explícita en la lengua escrita, ya que esta es un soporte, por lo general, conservador que inhibe y enlentece las dinámicas y tiempos usuales de los cambios.

d) Proceso estratificado o acumulativo. Se dice que el cambio es acumulativo o estratificado porque las formas o construcciones conservadoras conviven por siglos junto a las formas o construcciones innovadoras, muchas veces bajo un mismo exponente formal. Esta característica está en dependencia de las propiedades anteriores y se debe al hecho de que las innovaciones lingüísticas - denominadas también cambios o discontinuidades observables- nunca afectan a una categoría en su totalidad, sino que, en condiciones normales, afectan a pequeñas parcelas y a algunos ítems de esa categoría, de manera que la forma o construcción innovadora convive por largos periodos al lado de las parcelas y/o ítems categoriales aún no afectados por el cambio. Lo anterior garantiza que el cambio sea lento y garantiza que no se produzcan quiebres en la comunicación ni en la operatividad de la lengua.

La gráficas 1 y 2 a continuación muestran dos cambios sintácticos “normales", ya que en una larga diacronía los dos fenómenos en cuestión proceden según lo esperado en cuanto a gradualidad y lentitud, ya que ambos evolucionan o se modifican sin quiebres ni picos bruscos. La 
gráfica 1 deja ver la evolución de complementos circunstanciales iniciales o topicalizados ${ }^{2}$, del tipo en Argentina siempre como carne; en la noche lo hacemos, en lugar de siempre como carne en Argentina; lo hacemos en la noche, con los circunstanciales pospuestos al verbo y en posición final del sintagma verbal, que es el lugar no marcado y neutro para este tipo de complementos. Se observa una esencial estabilidad en la diacronía de la lengua, con un ligerísimo y sostenido aumento de complementos circunstanciales topicalizados, con un incremento mayor, pero casi imperceptible, en el siglo XVII, y a partir de entonces una esencial continuidad ${ }^{3}$.

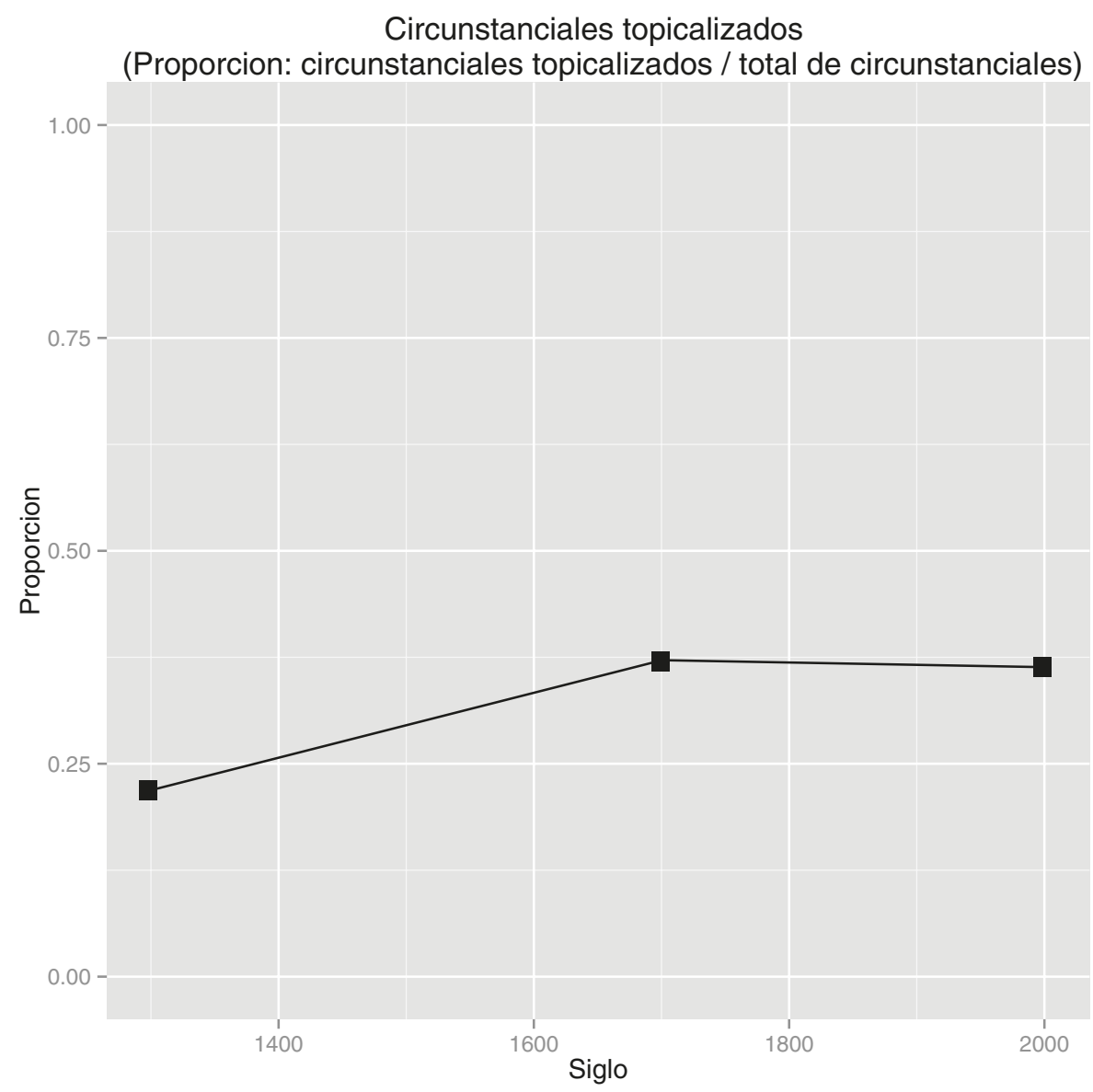

Gráfica 1. Un cambio sintáctico "normal”: topicalización de circunstanciales

2 Los datos cuantitativos proceden de Melis y Alfonso (2012); la interpretación estadística y la inserción en las dinámicas del cambio lingüístico son mías.

3 Topicalización de circunstanciales que es una estrategia recurrente de la literatura, mediante la cual el escritor primero codifica la escena y posteriormente pone en ella a los participantes — actantes, participantes o argumentos, como se les conoce en la lingüística-; pensemos, por ejemplo, nada más y nada menos, en el muy citado inicio del Quijote: “En un lugar de la Mancha..., un circunstancial topicalizado que abre la obra toda. 
La gráfica 2, por su parte, refleja cómo las subordinadas finales con verbo conjugado, del tipo te lo dije para que lo termines pronto; lo hicimos así para que lo piensen bien, han ido progresiva y lentamente cediendo su terreno funcional a favor de subordinadas finales introducidas por otros nexos, te lo dije a fin de que termines pronto; te invito a que lo pruebes. ${ }^{4}$ Al igual que en el cambio anterior, pero ahora en sentido inverso ya que se trata de una disminución, se observa un constante pero gradual decremento en el empleo de subordinadas con para que, sin quiebres ni inflexiones bruscas en ningún momento de la diacronía del español.

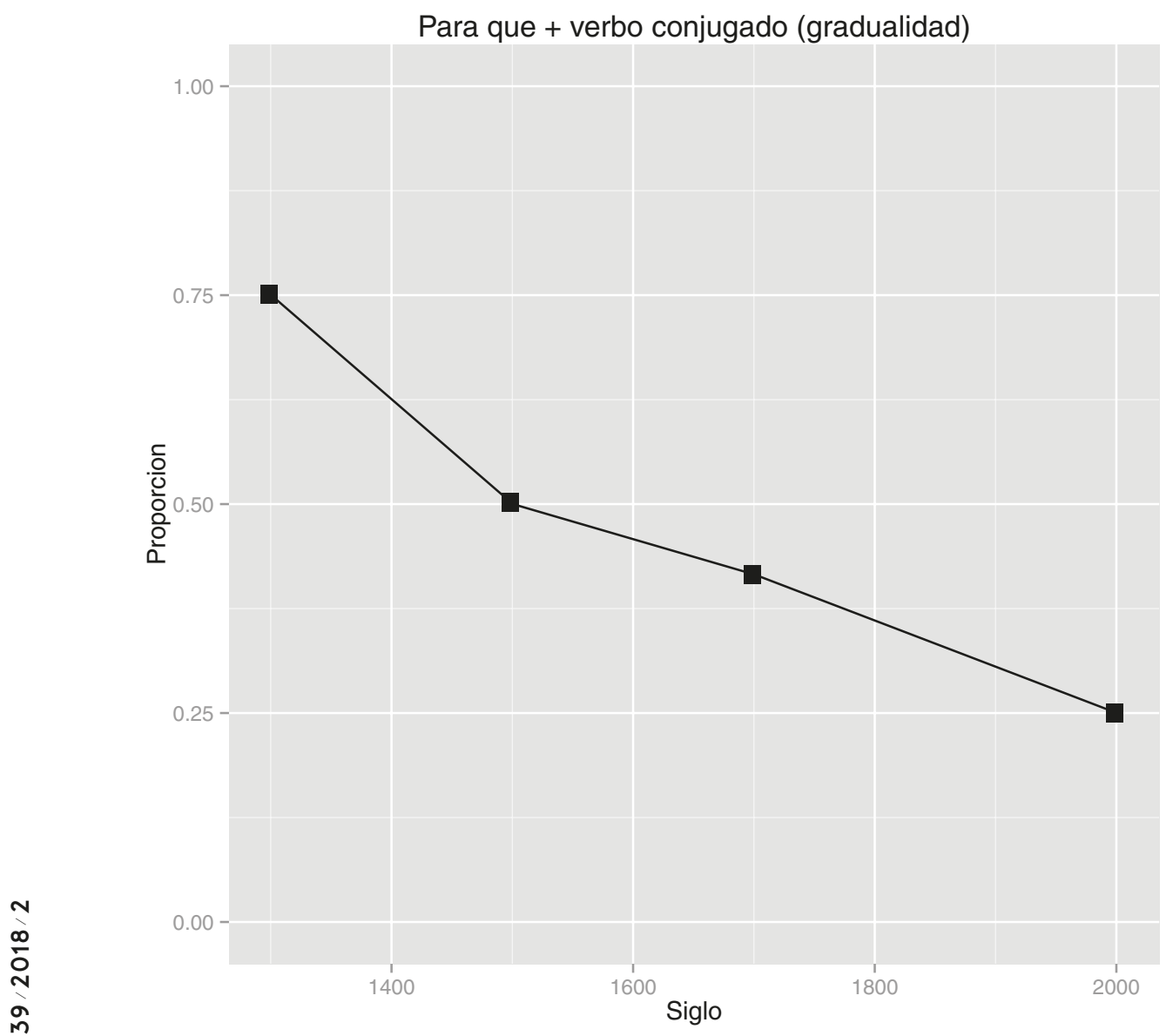

Gráfica 2. Otro cambio sintáctico "normal": para que + verbo conjugado

4 Los datos cuantitativos proceden de Silva (2012); la interpretación estadística y la inserción en las dinámicas del cambio lingüístico son mías. 


\section{El siglo XVII: un periodo lingüístico especial en la historia del español}

En este apartado analizo ocho zonas distintas de la sintaxis del español: 1. posición inicial de adverbios temporales aspectivos: aún, luego, todavía y ya; 2 . adyacencia al verbo de estos adverbios; 3. diacronía de la frecuencia general de empleo de los adverbios en -mente; 4. preposición $a+$ frase nominal de naturaleza léxica locativa: voy a la plaza; 5 . preposición entre + frase nominal: entre los ancianos; 6 . preposición por + frase nominal con núcleo abstracto: por las dudas; 7. preposición para + infinitivo: para terminar; 8 . subordinadas correlativas: consecutivas de intensidad: era tan grande su miedo que se quedó paralizado ${ }^{5}$. En los ocho cambios, el siglo XVII sufre un quiebre o inflexión fuerte que se escapa de la dinámica esperada o normal del cambio sintáctico expuesta en las gráficas 1 y 2 del apartado anterior.

El hecho de que zonas categoriales tan distintas de la sintaxis del español - preposicional, adverbial y subordinación varia - se comporten en la diacronía de un modo similar hace más robusta la hipótesis de que, desde un punto de vista estadístico, este siglo constituye un outlier en la periodización del español ${ }^{6}$. Es decir, la coincidencia de comportamientos en zonas tan distintas no puede deberse al azar, sino que habrá que buscar una causación necesaria, siguiendo a Sloman (2005), entre sintaxis histórica y otras disciplinas, en este caso, historia externa de la lengua. En este apartado expondremos los cambios y en el siguiente intentaremos acercarnos a algunas explicaciones de tal causación.

Todos los cambios, con el fin de establecer cierta comparabilidad entre los resultados, están sustentados en análisis y corpus con ciertas similitudes. Todos están basados en diacronías amplias, ya que inician en el siglo XIII y llegan hasta los siglos XX o XXI. Todos los fenómenos están fichados por muestreo al azar con intervalos sistemáticos de 150 o 200 años entre cada corte cronológico; todos los cambios fueron analizados sobre un universo de palabras similar para cada corte cronológico; en caso de que el capítulo no tuviera la homogeneización cuantitativa requerida respecto de los universos de palabras por corte cronológico, las cantidades netas que contenía el capítulo en cuestión fueron tratadas estadísticamente con el programa que abajo menciono con el fin de hacer comparables los universos de cada periodo. Las bases de datos sobre las que se soporta el análisis son amplias, entre 2500 y 6000 fichas por fenómeno. Todos los cambios analizan de tres a cinco obras por corte cronológico. Todos los análisis abarcan diversidad de géneros textuales, si bien todas las obras analizadas corresponden a prosa.

5 La fuente para estos cambios son diversos capítulos de la obra dirigida por Concepción Company Company, Sintaxis histórica de la lengua española. Tercera parte: Adverbios, preposiciones y conjunciones. Relaciones interoracionales, México: Fondo de Cultura Económica y Universidad Nacional Autónoma de México (2014). Los capítulos en que se exponen los respectivos temas son de las siguientes autorías: Magaña, adverbios aspectivos de tiempo; Company, adverbios en -mente; Company y Flores, preposición $a$; Hernández Díaz, preposición entre; Cacoullos y Walker, preposición por y preposición para + infinitivo; Parodi, oraciones consecutivas.

6 Un número nada desdeñable de cambios sintácticos, en otras muy diversas zonas sintácticas, confirman la caracterización del siglo XVII como un outlier diacrónico estadístico; por razones de espacio sólo analizo estos ocho. Para algunos otros cambios que ofrecen este mismo comportamiento del siglo XVII como un outlier, siempre como quiebre o generalización, cf. Company (2015), así como diversos capítulos de la Primera parte: La frase verbal y de la Segunda parte: La frase nominal, 2006 y 2009, respectivamente, de la obra, ya referida en la nota 5, Sintaxis histórica de la lengua española. Hay, desde luego, muchos otros cambios, pero son los menos, en los cuales el siglo XVII no se muestra como un outlier. 


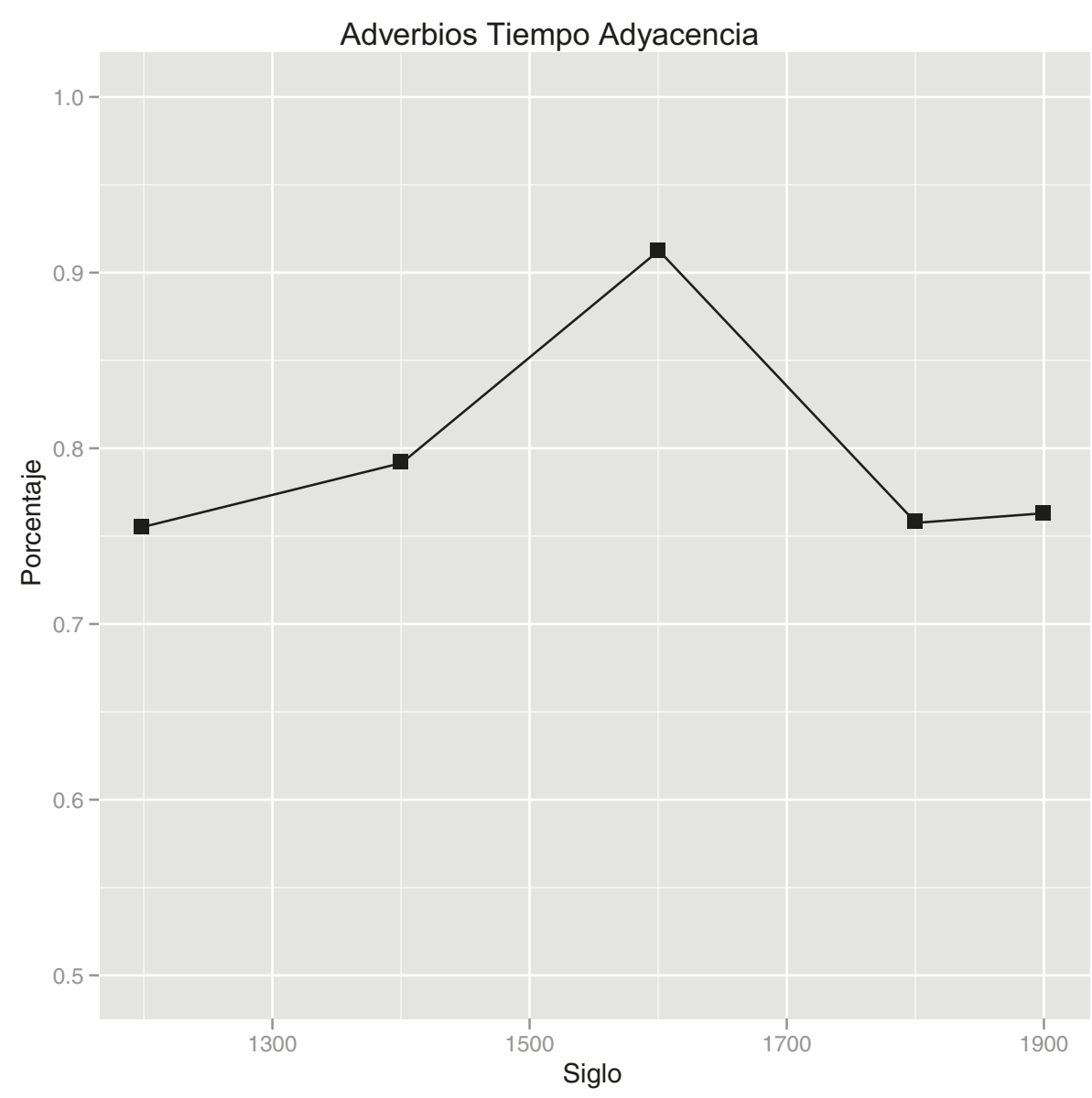

Gráfica 3. Adverbios de tiempo: adyacencia al verbo

Las herramientas metodológicas empleadas para analizar y exponer este comportamiento peculiar o especial del siglo XVII han sido las siguientes: en primer lugar, realizar un proceso de sistematización cuantitativa, expuesto en Company (2015); en segundo lugar, aplicar un estadístico $z$ a los datos cuantitativos generales por siglos que aparecen en los diversos capítulos de la obra ya mencionada; el estadístico $z$, también conocido como estimado $z$, es clave para saber si es significativo estadísticamente el quiebre que muestra el siglo XVII y es parte de la denominada prueba de diferencia de proporciones ${ }^{7}$, que consiste en comparar las ocurrencias de cualesquiera dos hechos o fenómenos, en el caso que nos ocupa, una estructura lingüística en dos siglos determinados, no necesariamente consecutivos; por ejemplo, XIII con XV, XVI con XVII, XVI con XVIII, XVII con XIX, etc. Un estadístico $z$ es significativo cuando el resultado es superior a 1.96 o inferior a 1.96. Los estadísticos $z$ de todos los fenómenos dieron un resultado positivo en el siglo XVII en cuanto a la significatividad del quiebre observado. Por último, los

7 Es de libre acceso y empleo en la página www.in-silico.net/statistics/ztest/twoproportion. 


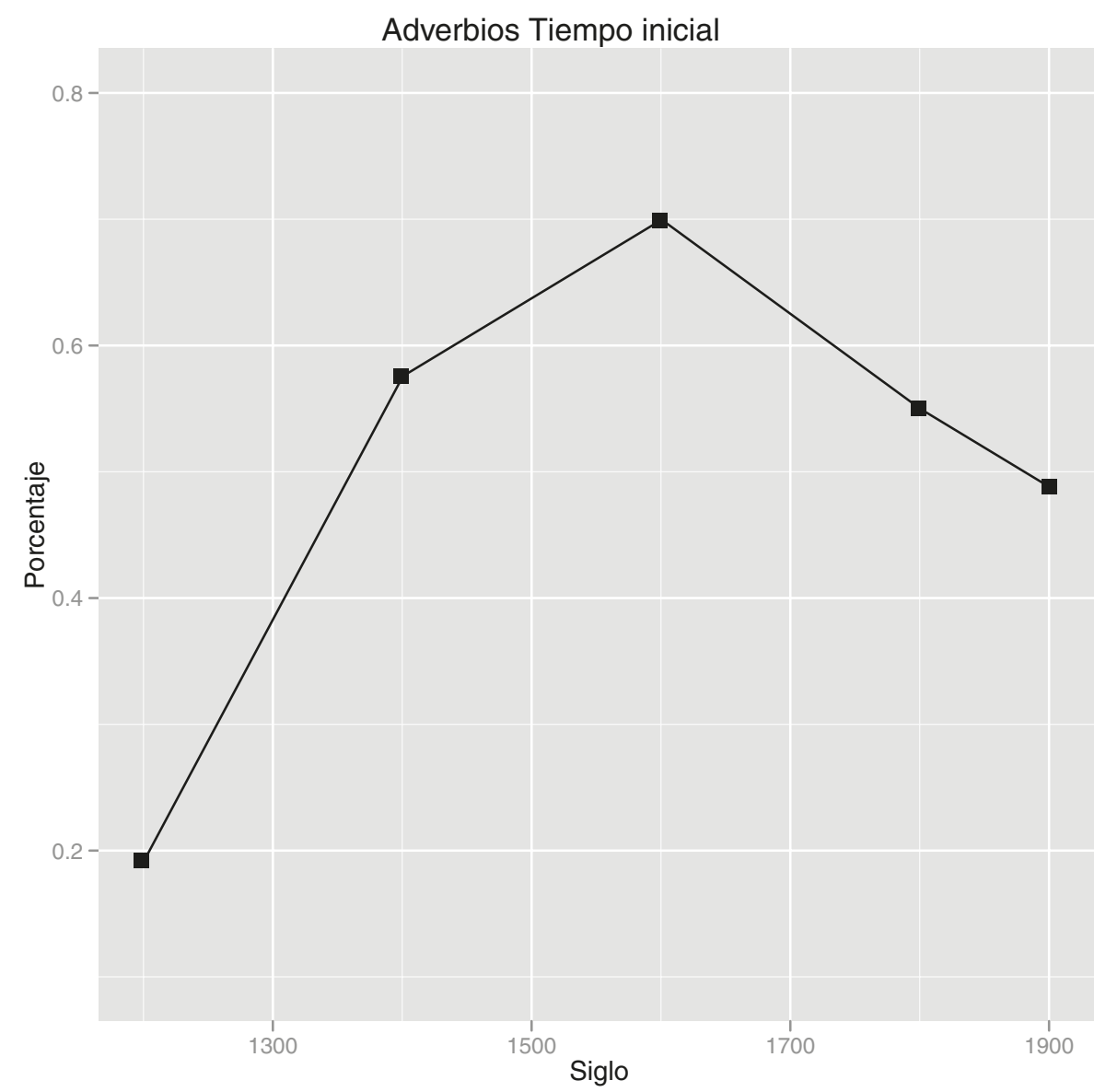

Gráfica 4. Adverbios de tiempo: posición inicial

resultados de la prueba de estadístico $z$ son convertidos a gráficas, que fueron elaboradas con lenguaje $R$, que son las que vamos a exponer y analizar a continuación.

En las gráficas 3 a 9 aparecen los cambios listados de 1 a 8 al inicio de este apartado. Las gráficas 3 y 4 miden la adyacencia al verbo y la posición inicial de los adverbios aún, luego, todavía y ya. Como adverbios que son, lo esperado es que mantengan, en una fuerte proporción, una posición adyacente al verbo y que si se separan de él y amplían su alcance para modificar toda la oración o adquirir funciones discursivas, como es común con ciertas clases de adverbios, se desplacen hacia los extremos, concretamente, hacia el extremo inicial. Efectivamente, eso es lo que puede verse en las dos gráficas: se mantuvieron adyacentes al verbo pero muchísimo más en el siglo XVII, y también se desplazaron hacia la posición inicial, pero muchísimo más en el siglo XVII. Tras este siglo, en ambas variables, la evolución "vuelve a la normalidad", ya que si el lector observa los cortes cronológicos precedente y subsecuente, siglos XV y XIX, respectivamente, se percatará de que están casi a la misma altura en frecuencia porcentual; es decir, el comportamiento de estos adverbios en los siglos XV y XIX está 


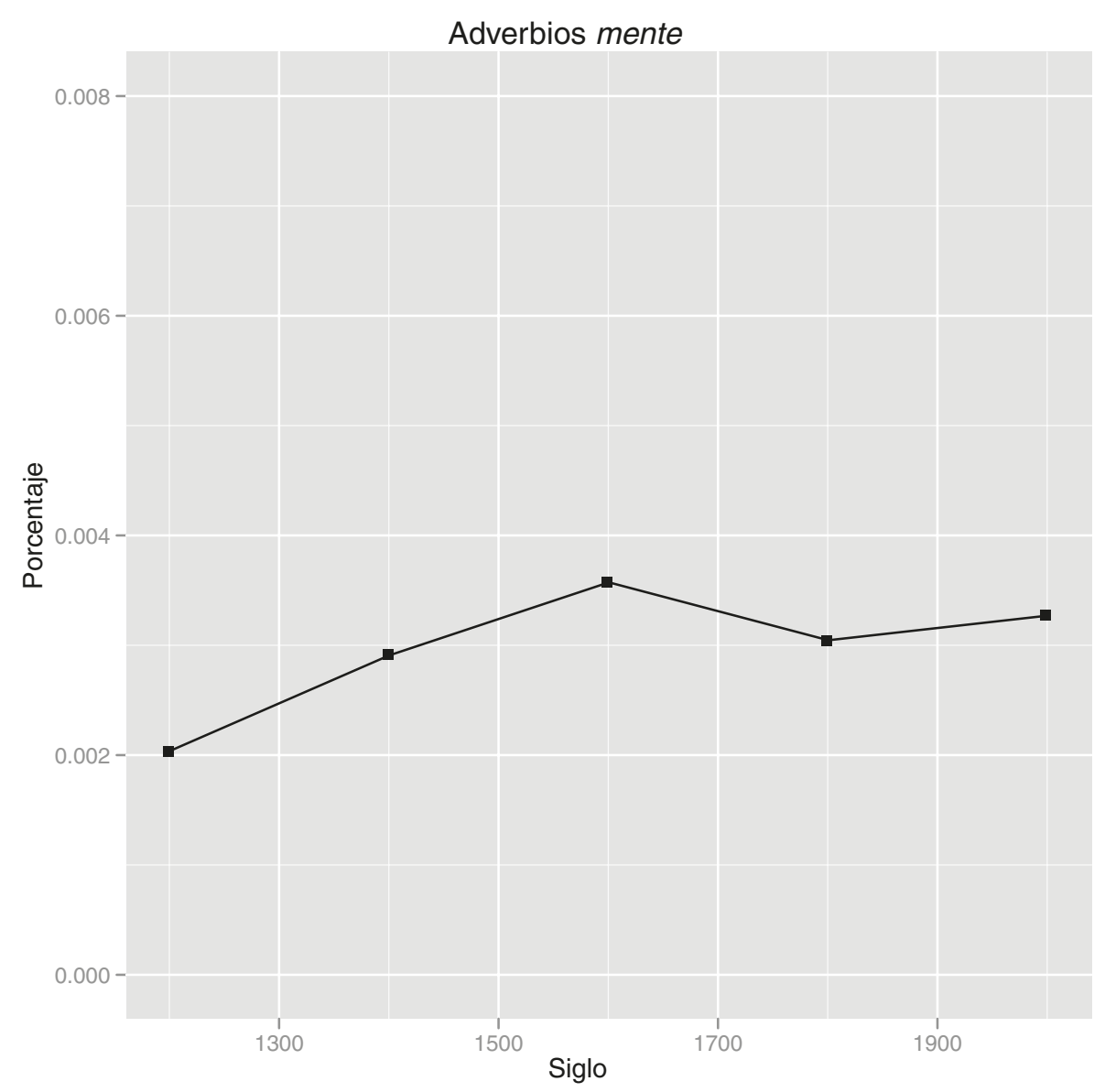

Gráfica 5. Adverbios en -mente: frecuencia general de empleo

casi nivelado o casi igualado antes y después del siglo XVII. Nos encontramos, por tanto, un antes y un después del siglo XVII. Este mismo comportamiento de antes y después del XVII se repite en otros varios cambios.

La gráfica 5 mide la frecuencia general de empleo de los adverbios en -mente. Como creación romance que son, lo esperado es que incrementen su frecuencia de uso, como efectivamente ocurrió, pero, de nuevo, el aumento se dispara en el siglo XVII, y de nuevo, el lector podrá observar que los cortes precedente y posterior a este siglo, XV y XIX, respectivamente, están prácticamente nivelados, con un ligero incremento en el siglo XIX y otro aumento más en el XXI; es decir, los incrementos fueron graduales y lentos, con excepción del ocurrido en el siglo XVII.

Las gráficas 6, 7 y 8 muestran cómo los rasgos léxicos de la frase nominal término de las preposiciones $a$, entre y por se desplazaron hacia la abstracción. El significado originario o etimológico de estas preposiciones era, como se sabe, de naturaleza locativa: directiva télica en el caso de $a$, estativa en relación a otro u otros puntos de referencia estativos, en el caso de entre, $\mathrm{y}$ de trayecto en el caso de por, pero con el paso del tiempo estas preposiciones incrementaron 
su capacidad de tomar frases más abstractas y menos locativas. La ganancia de significados más abstractos es la esperada en la evolución de la gramática cuando intervienen construcciones locativas, pero, lo interesante para los fines de este trabajo, es que ese movimiento hacia la abstracción siempre tiene un punto de inflexión fuerte en el siglo XVII, sea para generalizarse la estructura prepositiva en cuestión, sea para retraerse de forma brusca y luego recuperar frecuencia de empleo.

Por lo que respecta a la preposición $a$, gráfica 6, el aumento de términos abstractos, con el rasgo más humano - un ser humano es más abstracto que una locación geográfica, aunque ambos puedan ser seleccionados por la preposición $a$-, es constante pero lento y gradual desde el siglo XIII hasta el XVII, pero precisamente en este siglo se produce una muy fuerte inflexión, ya que a partir de entonces aumentan de manera mucho más ágil las documentaciones de $a$ con término frase nominal humana. En efecto, la preposición $a$ es una de las más frecuentes del español para introducir términos no locativos, ya que se volvió muy tempranamente marca gramatical: para introducir objetos directos humanos - "a personal" la denominaba Andrés Bello (1847/1978: \$889)—, se volvió también marca de objeto indirecto, que es casi siempre humano, es asimismo marca de muchos otros objetos directos abstractos e inanimados de diversa naturaleza léxica, introduce numerosos complementos modales, todos con término nominal abstracto, además de muchas otras funciones que requieren términos abstractos. Ese camino hacia la abstracción, lento antes del XVII y muy fuerte a partir de él, es lo que deja ver la gráfica 6 .

En los ejemplos de (1) abajo, puede apreciarse cómo la preposición $a$ aparece introduciendo términos abstractos de diversos tipos semánticos y en funciones diversas. En (1a) Quevedo emplea a para introducir un objeto directo inanimado abstracto, la gran cosecha de redondillas, canciones y sonetos, con el resultado de que Quevedo parece adelantarse a su tiempo en el empleo de esta preposición, porque aun hoy ese tipo de objetos directos inanimados abstractos es muy reacio a tomar preposición. De hecho, El Buscón abunda en construcciones prepositivas caracterizables como "muy modernas", que llaman poderosamente la atención a cualquier estudioso de la diacronía del español ${ }^{8}$. En (1b) Quevedo emplea una construcción prepositiva con término abstracto, riesgo, cuya ubicación sintagmática genera ambigüedad de lectura: bien como objeto directo de advertir con una subordinada relativa de riesgo, en cuyo caso todavía hoy el español estándar emplearía ese objeto directo sin preposición, el riesgo, o bien como régimen prepositivo adelantado de ponía, en cuyo caso también el español actual estándar preferiría otra preposición, en riesgo. Sea que al riesgo es un objeto directo prepositivo sea que es una prolepsis de poner, el autor logra énfasis expresivo porque la preposición otorga un efecto de dinamismo directivo e inminencia, ya que, como dijimos, el significado etimológico de $a$ es directivo télico hacia una meta, dinamismo que se debilitaría, o incluso desaparecería, al eliminar la marca prepositiva. En ( $1 \mathrm{~cd})$, Cervantes y un documento jurídico casi coetáneo del autor, emplean complementos de modo con sustantivos abstractos introducidos por la preposición $a$. Los objetos directos abstractos prepositivos y este tipo de complementos modales se vuelven mucho más frecuentes a partir del siglo XVII.

8 Cf. los datos sobre uso innovador de la preposición a en el XVII expuestos en Company y Flores, en el capítulo de la obra ya aludida Sintaxis histórica de la lengua española. Tercera parte. 


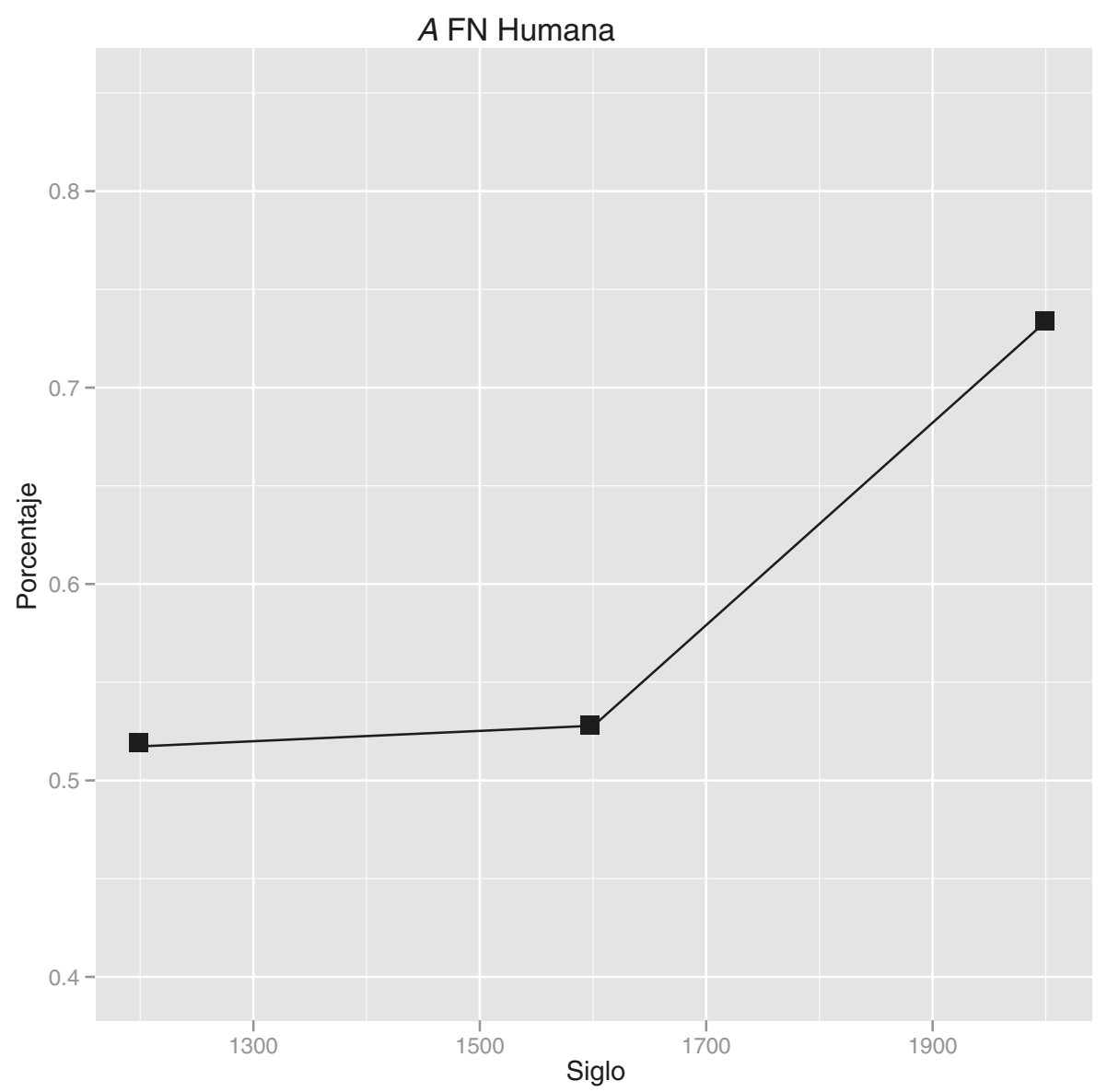

Gráfica 6. $A+$ FN: Incremento de núcleos humanos de la frase nominal término

(1) a. Advirtiendo a la gran cosecha de redondillas, canciones y sonetos que había habido en estos años fértiles (Buscón, 3.151).

b. No advertí al riesgo que me ponía (Buscón, 10.255).

c. Sepa vuestra merced que esto de azotarse un hombre a sangre fría es cosa recia (Quijote. Segunda parte, 59.1169).

d. A donde solían estar muchas veces a solas (Documentos lingüísticos de la Nueva España, año 1621, 83.251).

En el caso de la preposición entre, gráfica 7, se observa una ganancia de abstracción muy fuerte en el paso de los siglos XVI al XVIII, que son los dos cortes cronológicos, precedente y subsecuente, seleccionados para el estudio de esta preposición por Hernández Díaz en la obra Sintaxis histórica de la lengua española. Ello significa que el siglo XVII fue el momento de estandarización o generalización fuerte de los términos abstractos no locativos con entre, del tipo 


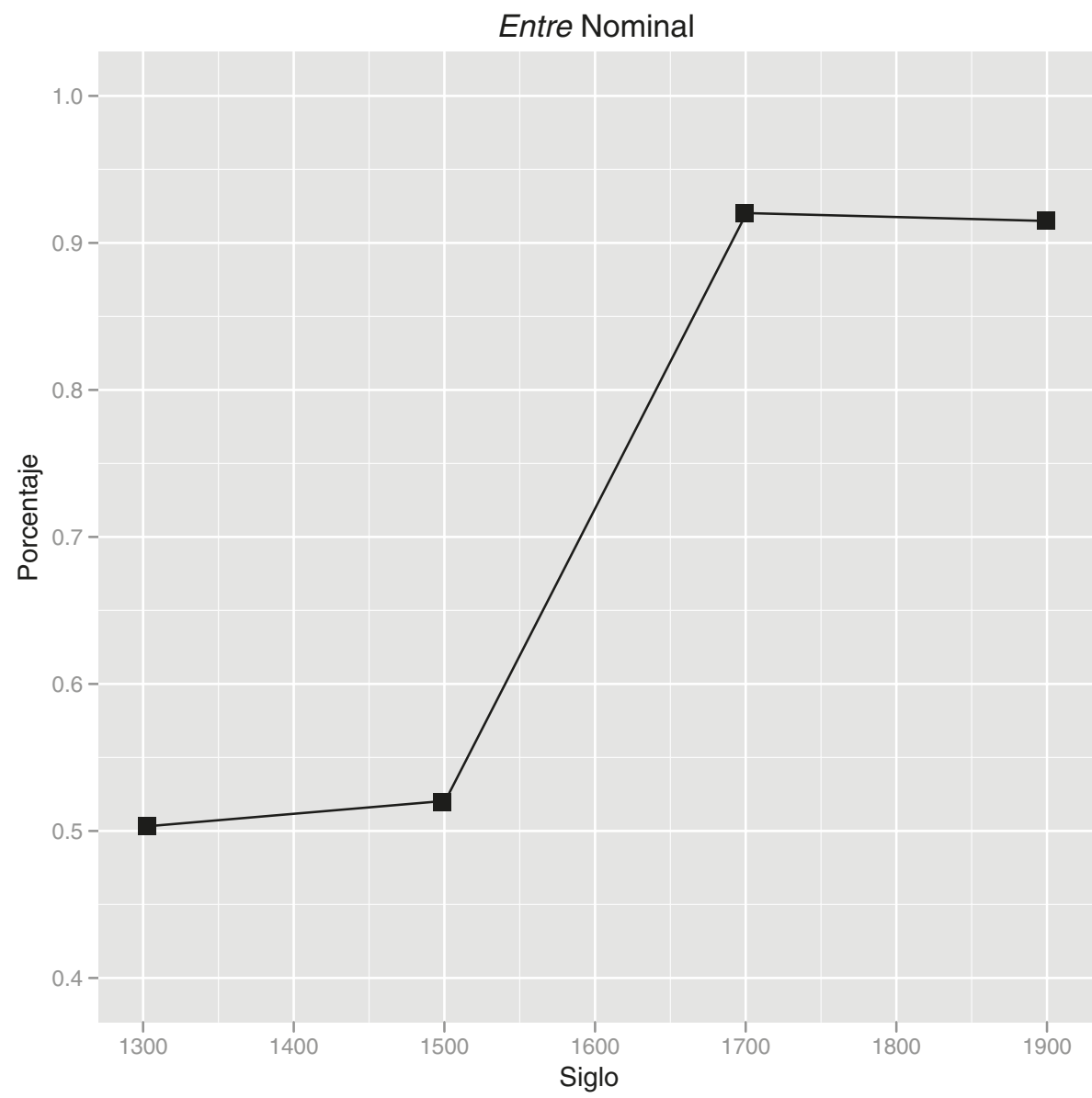

Gráfica 7. Entre + FN: abstracción de la frase nominal término

entre todos, entre esto y aquello, y que a partir de este siglo se mantuvo muy elevada la capacidad de entre de tomar términos no locativos.

Por su parte, en el caso de la preposición por, gráfica 8, se aprecia una diacronía consistente en una esencial estabilidad, una frecuencia muy elevada, por eso aparece la línea evoluctiva hasta arriba en la gráfica; se observan también vaivenes de aumentos y disminuciones de términos abstractos, del tipo por casualidad; por ejemplo, vaivenes que son lógicos porque por, a diferencia de $a$, no se ha vuelto preposición obligatoria de ninguna estructura del español. Nos interesa ahora solamente dirigir la atención al hecho de que de nuevo el siglo XVII despliega el cambio más brusco en los altibajos de la evolución de por, ya que muestra el retraimiento más fuerte y significativo de toda la diacronía de esta preposición.

Las oraciones consecutivas de intensidad, era tan fuerte que venció a todos, no sabe tanto como tú, experimentan un incremento muy fuerte en el paso del siglo XII al XIII, gráfica $9^{9}$, y después

9 El aumento fuerte inicial que muestra la gráfica 9 no debe atribuirse, en mi opinión, a un incremento en la frecuencia real de empleo de estas oraciones en la lengua, sino al hecho de que para el siglo XII sólo se analiza un texto, 


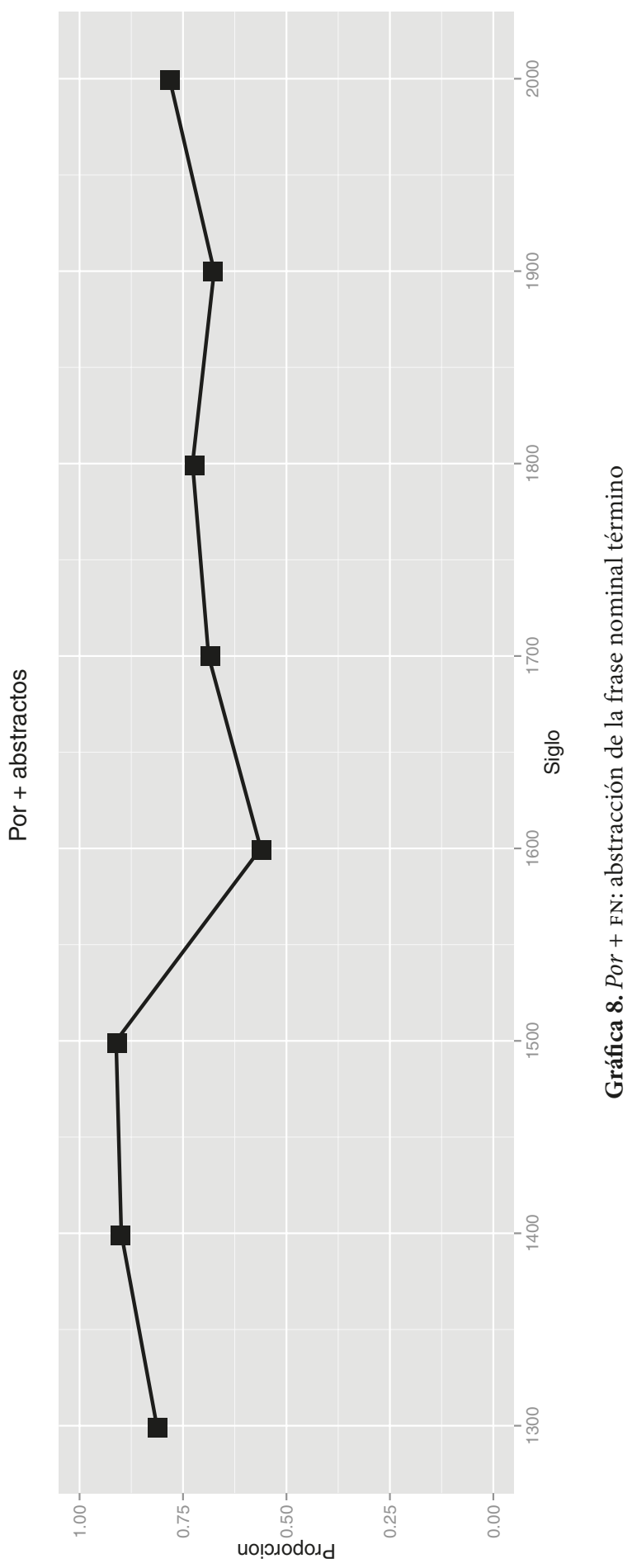




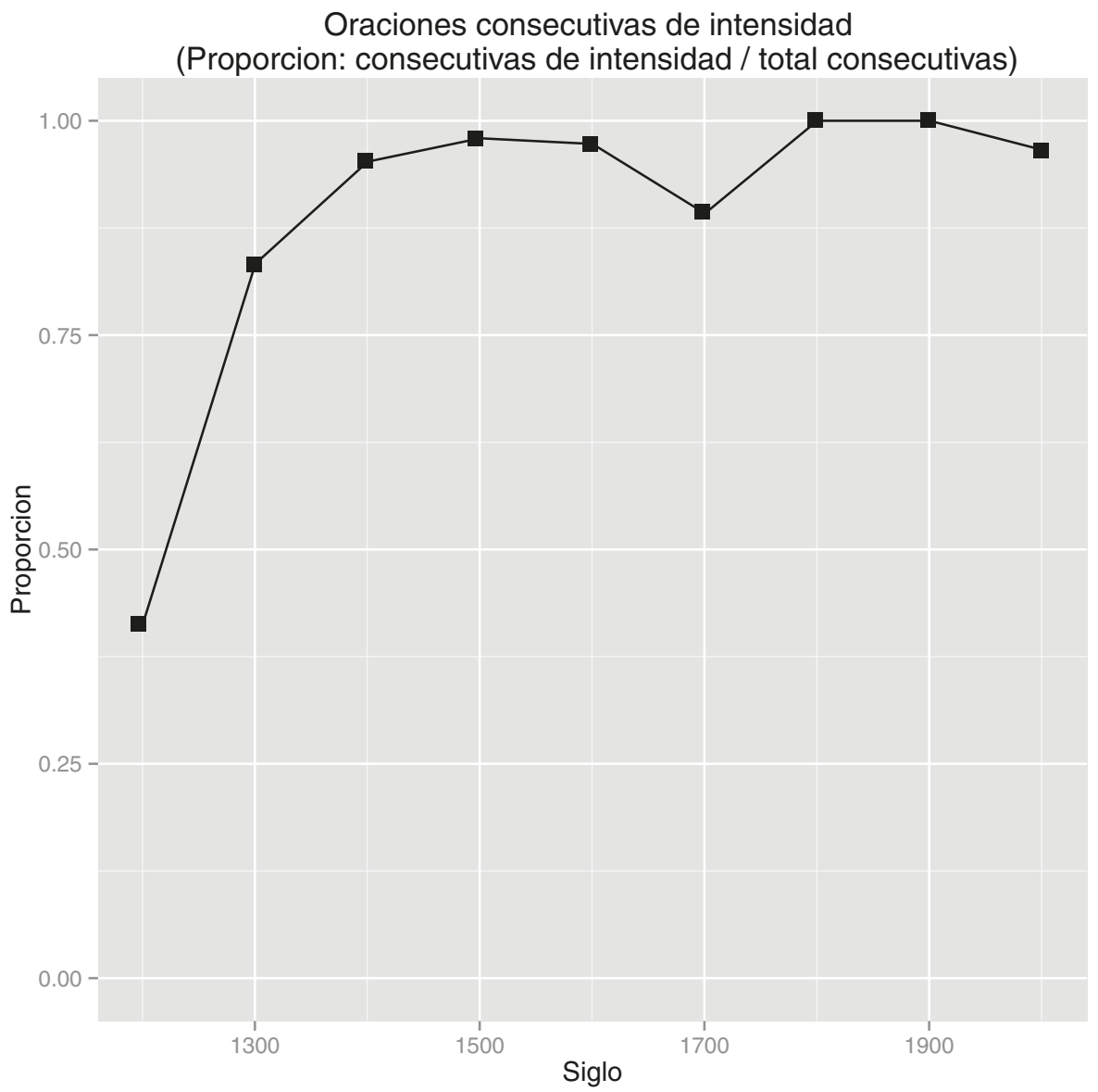

Gráfica 9. Oraciones consecutivas de intensidad: frecuencia general de empleo

se mantienen con elevada frecuencia y bastante estabilidad excepto en el siglo XVII en que, como muestra la gráfica, retraen de manera brusca su vitalidad. De nuevo, como en cambios anteriores, el siglo XVII supone un quiebre en la esencial continuidad y gradualidad de los cambios, manifestado en forma de retraimiento esta vez; de nuevo, los siglos XVI y XVIII están mucho más igualados entre sí, o son más semejantes, en el empleo de estas construcciones, que cualquiera de ellos respecto del XVII.

La gráfica 10 concentra varios de los cambios previamente expuestos y algunos otros analizados en Company (2015), con el mismo comportamiento de quiebre o generalización. La gráfica, por tanto, muestra el conjunto de varias diacronías sintácticas amplias en cuanto a profundidad

el Cantar de mio Cid, porque, de hecho, no conocemos otra obra literaria en castellano para ese siglo, pero a partir del siglo XIII contamos con una rica y diversa producción textual salida de los scriptoria alfonsíes, motivo por el cual la frecuencia se eleva mucho, porque hay muchos más textos analizados y por tanto hay más construcciones consecutivas. En los siglos subsecuentes el capítulo que trata estas construcciones en la ya mencionada Sintaxis histórica de la lengua española, a cargo de Parodi, mantiene una densidad textual similar de siglo a siglo. 


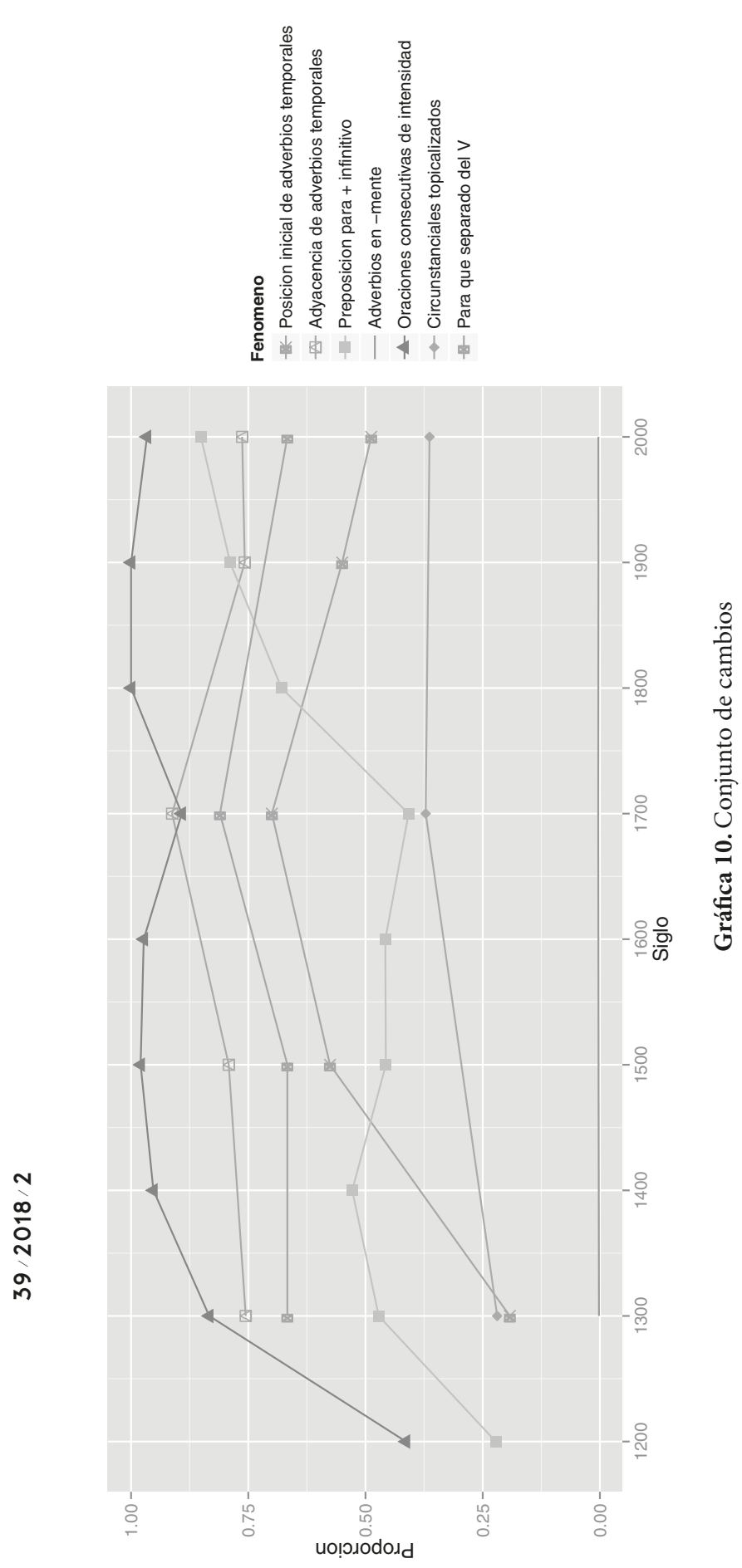


histórica. Puede verse que la zona de la gráfica correspondiente al siglo XVII es casi un "volcán" de hoyos y picos evolutivos - si se me permite tal expresión - frente a otros periodos que parecen no quebrar la esencial gradualidad de la lengua o la quiebran de manera mucho menos brusca. La diacronía de los adverbios en -mente aparece hasta abajo de la gráfica y se vuelve casi imperceptible el pico del XVII que afloraba en la gráfica individual correspondiente, la número 5 , porque al ser analizado en comparación con otros fenómenos, estos adverbios son mucho menos frecuentes que otras estructuras, motivo por el cual el análisis estadístico le otorga esa ubicación.

La gráfica 10 arriba nos informa de varios aspectos interesantes respecto del lugar que el siglo XVII ocupa en la historia sintáctica del español. Por un lado, surge ante los ojos del lector una gran paradoja porque se ven dos modos de cambio: es un periodo de retracción de algunos fenómenos y al mismo tiempo es un periodo de gran generalización y estandarización de otros muchos cambios. Por otro lado, el siglo XVII puede ser calificado un periodo de quiebre, en el sentido de que el corte cronológico siguiente, sea el siglo XVIII sea el XIX, vuelve, grosso modo, a la manifestación cuantitativa del periodo precedente, sea este el siglo XV sea el XVI. Puede verse también en la gráfica que el quiebre es casi siempre hacia arriba, es decir, exuberancia o "exceso de" la estructura en cuestión, más que hacia abajo, con dos excepciones, por con término FN de núcleo abstracto y consecutivas de intensidad que experimentan retraimiento de la frecuencia de empleo. Finalmente, la gráfica 10 comprueba que el siglo XVII es una centuria de fuertes generalizaciones de frecuencia que llevan a la estandarización de la forma o construcción en cuestión, volviéndola estándar, general o no marcada en nuestra lengua. Es decir, a partir del siglo XVII se generaliza el fenómeno en cuestión y se manifiesta casi tal cual a como se comporta en el español actual. Hay que señalar también un rasgo característico de la lengua del XVII, a saber, es un outlier en frecuencia o vitalidad de empleo de las formas, un desvirtuador cuantitativo estadístico, pero es una lengua canónica y normativa ya que no exhibe estructuras no esperadas o "raras" desde el punto de vista lingǘstico, al menos no en los cambios estudiados en este trabajo y en otros que se analizan en los estudios mencionados en las notas precedentes ${ }^{10}$.

\section{Las "anomalías" estadísticas del siglo XVII a la luz del diálogo interdisciplinario}

La recurrencia estadística del siglo XVII en mostrar esta centuria como un periodo de ruptura gramatical obliga a formular, al menos, dos preguntas: a) ¿pudiera ser el siglo XVII un caso de cambio sintáctico "sin" sintaxis? Entendido este "sin" en el sentido de que sería posible que

10 Cosa lógica, por otra parte, porque no hay nada no esperado, no canónico, en la gramática, porque de haberlo, aquella dejaría de ser gramática. Sin embargo, sería interesante preguntarnos si el abuso que hacen algunos autores de la época de ciertas construcciones o una alteración desmedida del órden de palabras puede ser calificado de canónico. Por ejemplo, por citar sólo un caso, Juan de Zabaleta en sus novelas Día de fiesta emplea adjetivos antepuestos a un extremo realmente inusual ya para la época, el doble de anteposición que otros escritores, como se aprecia en el ejemplo siguiente: "No hay más indigna parte que la mano del que tercia un vicio ni más desperdiciado abandono que el que se pone en aquella mano" (pág. 130, edición de Castalia). Gramaticalmente, los adjetivos calificativos fueron progresivamente posponiéndose al sustantivo en la historia del español, y ya para el siglo XVII la prosa no literaria de la época los usa por lo general pospuestos. 
la motivación de la peculiar manifestación estadística expuesta en el apartado anterior no se encuentre en la historia interna, en la gramática histórica, sino en la historia externa, en cuyo caso, $b$ ) la historia del periodo, la cultura y la estructura social del momento, ¿cómo inciden en el cambio sintáctico? En suma, el llamativo, casi sorprendente, comportamiento estadístico del siglo XVII requiere - pide a gritos- para su explicación un diálogo interdisciplinario entre historia interna e historia externa, y requiere que nos acerquemos a esta última de un modo incluyente, es decir, desde las varias disciplinas que la integran.

Ha sido ampliamente señalado en estudios de historia, literatura y sociología que el siglo XVII es un periodo de muchas aristas contradictorias que, entrelazadas, generan una unicidad, unicidad que es, justamente, el momento peculiar y, al parecer, único que el siglo XVII constituye para la literatura y la cultura en lengua española (Elliott 1963; Hatzfeld 1964; Montaner 1989; Lynch 2007; Maravall 2012; Ruiz Pérez 2010, entre otros muchos).

Intentaré aportar una explicación de cómo algunas de esas aristas multiangulares, sociales, históricas, políticas y culturales en general, pudieron incidir en la gramática del periodo bajo estudio. Examinaré muy brevemente por razones de espacio cinco ángulos: 1. movimientos políticos y movimientos poblacionales en este siglo; 2 . creación de nuevos modelos culturales, en particular, la creación de la cultura de masas en el XVII; 3. enorme desarrollo de la imprenta en este siglo y desarrollo de conciencia lingüística con la consecuente compleja tensión entre escritura y oralidad en la literatura del momento; 4. estructura social, y 5 . arraigo de dos modelos estéticos literarios complementarios. Cada uno de estos cinco ángulos despliega, en opinión de los estudiosos arriba citados, un comportamiento en sí mismo un tanto contradictorio porque, con frecuencia, su gestación y efecto tenían motivaciones dobles, o incluso triples, todo lo cual permite, en mi opinión, entender mucho mejor e incluso generar una explicación de la complejidad sintáctica del periodo en forma de fuertes generalizaciones a la par que de fuertes retracciones.

Es decir, la hipótesis aquí sustentada es que los resultados sintácticos contradictorios del siglo XVII para la diacronía del español pueden tener una explicación en aspectos sociales, culturales y políticos cuyas dinámicas son también un tanto contradictorias. Y no es de extrañar, porque, finalmente, la lengua es el soporte de la conceptualización y de la visión de mundo de una sociedad, y aquella y estas se requieren mutuamente, sin olvidar lo bien sabido de que la lengua es un sistema de símbolos abstractos y arbitrarios.

1. Movimientos politicos y movimientos poblacionales. Hay tres hechos político-sociales señalados por Lynch (2007) que, cabe pensar, generaron efectos lingüísticos encontrados. Por un lado, el siglo XVII fue un periodo de fuertes cambios sociales, manifestados en gran medida como una inconformidad social muy extendida que provocó levantamientos varios y subversiones en ciertas regiones de España. Tales movimientos y subversiones debieron generar una fuerte movilidad social y poblacional manifestada, en lo lingüístico, en un dinamismo en forma de cambios y discontinuidades sintácticas. Por otro lado, el siglo XVII fue un momento de fuerte afirmación de las autonomías regionales - una prueba de ello es que Cataluña se deslinda del poder monárquico central y se niega a tributar a la Corona-, hecho que debe ponerse en relación con las subversiones poblacionales ya señaladas, y fue, a la vez, el momento en que Felipe III expulsa a los moriscos. Afirmación de autonomías más expulsión de moriscos debió facilitar 
la estandarización del castellano, puesto que debió crear un efecto de "aislamiento", al menos oficialmente, y de empoderamiento de esta lengua respecto de las lenguas vecinas, con la consecuente homogeneización y consolidación de aquella, al punto de que el castellano se vuelve, posiblemente por primera vez en la historia del español, una verdadera lengua nacional en la práctica y uso. Por último, el siglo XVII, sobre todo en el reinado de Felipe III y aún más en el de Felipe IV, es un momento de migraciones masivas a la ciudad, hecho que debió incidir en ruptura y reorganización de redes sociales, en el sentido de Milroy y Milroy (1997), ruptura que debió crear discontinuidades gramaticales importantes además de que debió impactar la lengua urbana con muchas y variadas formas de la oralidad regional, que sumadas a la oralidad urbana, crearon un efecto de koineización, al tiempo que crearon dificultades para una adecuada estandarización lingüística y dieron pie a quiebres y retracciones. En suma, los cambios políticos y sociales aquí expuestos crean un simultáneo doble efecto distinto en la lengua española: las subversiones y migraciones son un agente dinamizador y generan quiebres, pero la expulsión de los moriscos y la afirmación de autonomías regionales fueron un agente estandarizador para la lengua española.

2. Creación de nuevos modelos culturales: cultura de masas vs. fuerte individualismo. Como señalan Hatzfeld (1964) y Maravall (2012) repetidamente en sus respectivas obras, el siglo XVII es el momento en que irrumpe en la sociedad española la cultura de masas. Para que esta tenga un efecto exitoso como modelo cultural consumible por parte de la sociedad, en especial por las clases populares, se requiere que sea muy igual y se creen y difundan estereotipos, una cultura de molde, de guión preestablecido - baste recordar que ese es el objetivo del Arte nuevo de hacer comedias de Lope, crear un molde, una "receta", de cómo hacer teatro-, a la vez que se requiere que esos estereotipos y moldes sean remplazados cada cierto tiempo y con cierta rapidez para que los modelos sigan siendo consumidos. Sin duda estas dos características de la cultura de masas, molde y cambio, debieron generar un efecto lingüístico de homogeneidad, generalización y estandarización, por una parte, pero simultáneamente de quiebres y dinamismo, por otra.

Por otro lado, y como contraposición a la cultura de masas, es un hecho bien estudiado que el siglo XVII es un periodo, posiblemente $e l$ periodo, de un elevado individualismo en la creación literaria, manifestado, por ejemplo, en una cantidad nada desdeñable de hapax, en Cervantes o en Góngora por ejemplo, entre otros autores, varios de los cuales llegaron a la lengua cotidiana y se difundieron en la oralidad. Tal individualismo debió crear una cierta resistencia a la generalización de estructuras sintácticas, con un efecto contrario a la homogeneización provocada por la cultura de masas. Y dado que la sintaxis histórica depende en una gran medida de las obras literarias para obtener datos de lengua, este individualismo, carente de interés, en principio, para la gramática, no así para la estilística, queda reflejado en las diacronías sintácticas.

3. Enorme desarrollo de la imprenta y desarrollo de conciencia lingüística. Un hecho comentado por muchos estudiosos del siglo XVII es que en este siglo se desarrolla enormemente la cultura impresa debido a la alta demanda de obras y de la lectura y representación, en su caso, de estas ${ }^{11}$.

11 Cf. Maravall (2012), Ruiz Pérez (2010: cap.2), y varios artículos del número monográfico Edad de Oro (1988) referido en la nota 1. 
La consecuencia lingüística esperada de este desarrollo es que se reduzcan los cambios en la lengua o se hagan más lentos porque, como ya comenté al inicio de este trabajo, la imprenta produce un efecto de generalización de formas y construcciones, además de que las sociedades cultas opacan la oralidad mucho más que las comunidades iletradas y, por lo tanto, se oculta el dinamismo de la lengua en su uso real oral (Haugen 1966; Ammon 2004). Pero al mismo tiempo, el siglo XVII es un periodo de una elevada sensibilización lingüística, de una fuerte conciencia de lengua y de una alta elaboración lingüística, manifestadas en la constante crítica ejercida por los escritores, en las tertulias, en la creación de academias y en el teatro, entre otros, al punto de que Menéndez Pidal (1991: 173) habla de la "literaturización del habla común” en el periodo de los Austrias. Todo lo cual podría haber producido una compleja tensión entre escritura y oralidad en la literatura del momento, reflejada en las generalizaciones y en las discontinuidades sintácticas observadas en el apartado precedente. Volvemos a encontrarnos, por tanto, con la convivencia de funcionamientos sociales opuestos en la cultura y sociedad del siglo XVII, estabilidad y cambio, convivencia que podría explicar las dos manifestaciones lingüísticas evolutivas contrapuestas ya vistas para este periodo.

4. Estructura social. Un dato recurrente aportado por Lynch (2007) es que durante el siglo XVII la estructura social fue sumamente conservadora, jerárquica y estamentaria, lo cual, cabe pensar, habría producido cierta retracción en las dinámicas usuales del cambio lingüístico, y, ciertamente, algunas construcciones sintácticas del apartado anterior dejan ver fuertes retracciones en ese siglo, si lo insertamos en una amplia diacronía de la lengua. Al mismo tiempo, esa sociedad jerárquica y estamentaria estuvo caracterizada por un fuerte dirigismo y autoritarismo que, para su eficaz funcionamiento desde el poder central monárquico, habría requerido una lengua general y estándar para vehicular más fácilmente tal autoritarismo. De nuevo, un comportamiento social con dos ángulos que inciden, asimismo, en dos efectos lingüísticos.

5. Arraigo de dos modelos estéticos literarios complementarios. El siglo XVII es el momento del Barroco y este, como se sabe y ha sido dicho tantas veces, es un movimiento de claroscuros y de ángulos opuestos complementarios (Hatzfeld 1964: cap. 3; Maravall 2012: cap. 4). Es, por un lado, el siglo de la desmesura y de la exageración, manifestadas en la lengua, por ejemplo, en muchas subordinaciones con un efecto de recursividad muy compleja y de párrafos muy extensos, en abuso de adverbios y formas varias de la modalización, o en abuso en el uso de adjetivos calificativos y, sobre todo, en su anteposición al sustantivo, cuando en la lengua no literaria de ese periodo, y desde mucho antes en el español, ocupan un lugar no marcado pospuesto al sustantivo. Un buen reflejo de exageración y desmesura lo constituyen, por ejemplo, los sermones de la época. Y pensemos sin duda en Góngora, para citar un autor de primera línea, y pensemos en Juan de Zabaleta, un “segundón” comparado con aquel; en ambos, los recursos sintácticos empleados son muy semejantes, aunque la sabiduría estilística de uno y otro, con el consecuente efecto estético, sean muy diferentes. Y frente a, y junto a, la desmesura y la exageración, el Barroco es un movimiento de la prudencia y el laconismo. Baste pensar, también, en otro tipo de sermones comunes en la época y en escritores como Quevedo o en Gracián, muy distintos entre sí pero con recursos sintácticos similares. Sin duda esta dualidad complementaria del Barroco debió incidir en la lengua, creando un efecto general de "montaña 
rusa” en los cambios, que es lo que apreciamos en la gráfica 10 con el conjunto de los cambios analizados. Un efecto, me atrevo a decir, de gigantesca convulsión lingüística, y no hay tal en el siglo XVI ni en el siglo XVIII.

Si parafraseáramos la conocida frase del prólogo de la Gramática de Antonio de Nebrija, enunciándola al revés: "porque la historia es compañera de la lengua", podríamos entender y explicar mejor por qué el siglo XVII produce ese efecto de convulsión y de opuestos lingüísticos. La lengua del XVII, como cualquier lengua, es el soporte fundamental de toda interacción social y fue el soporte de esas múltiples aristas paradójicas que construyen la cultura del Barroco y construyen la historia y sociedad de ese siglo. Las dos manifestaciones casi opuestas de cambio lingüístico que se observan en el XVII se explican mucho mejor en el conjunto de aparentes opuestos culturales, sociales, históricos y literarios que configuraron y construyeron este complejo periodo.

\section{Conclusiones}

Desde la teoría lingüística y el método sintáctico, hemos visto que el empleo de modelos estadísticos se constituye en una herramienta valiosa para los análisis diacrónicos y análisis de periodización de una lengua, porque muestra lo sabido y hace "ver" lo intuido o no sabido, y es una herramienta valiosa porque a las descripciones añade explicaciones o, al menos, obliga a hacerse preguntas para buscar explicaciones en otro nivel, no necesariamente lingüístico. Hemos visto, asimismo, que la frecuencia de empleo es un síntoma de cómo se comporta la gramática y ayuda a establecer generalizaciones - generalización que es casi un reto en una disciplina que se presta y se mueve naturalmente en la atomización, como es la sintaxis histórica-, ayuda a valorar y a comprobar.

Hemos mostrado que la unión del análisis cuantitativo-estadístico con el cualitativo permite sobrepasar el análisis individual del texto y sobrepasar asimismo el análisis del sistema en abstracto, carente de "carne" textual y cultural.

La conclusión lingüística obligada que surge sin duda de los cambios diacrónicos expuestos en el apartado $\$ 4$ es que debemos preguntarnos qué es un cambio lingüístico “normal” o, en otras palabras, cuestionarnos si la gradualidad y lentitud son características inherentes y definitorias de los procesos de cambio sintáctico, como hasta ahora hemos dicho en la teoría del cambio sintáctico.

Para la historia de la lengua, hemos obtenido, asimismo, información relevante. Hemos visto que no es un hecho dado que el siglo XVII sea un periodo áureo, no al menos para la sintaxis histórica. Ni tampoco es un hecho dado que la lengua del siglo XVII sea un modelo, o al menos, a la luz de los datos, debemos preguntarnos qué es un modelo de lengua.

Hemos mostrado que el siglo XVII constituye un outlier estadístico, sin duda, porque no puede deberse al azar que ocho cambios en zonas gramaticales distintas se comporten igual, en cuanto que muestran quiebres y generalizaciones que desvirtúan y cuestionan la gradualidad y normalidad de los procesos de cambio sintáctico. Sin duda alguna, el siglo XVII es un periodo especial y único, que muy posiblemente por sí mismo constituye una etapa propia en la 
periodización sintáctica del español; fue en sí mismo una catástrofe elemental de la historia del español, considerada esa expresión en su sentido técnico a la luz de la teoría de las catástrofes.

La aportación más interesante de este trabajo ha sido, a mi modo de ver, cómo se pueden enriquecer varias disciplinas - la lingüística, sin duda, pero también la literatura o la estilística-, si se intenta un análisis interdisciplinario basado en datos específicos y alimentado desde la historia y desde la cultura del periodo bajo estudio. Análisis interdisciplinario que no es sino un regreso al quehacer de la filología tradicional.

\section{Referencias bibliográficas}

Abad, F. (2004). Diacronía y sincronía del español. Cauce. Revista de Filología y su Didáctica, 27, 7-26.

Aguilar, A.; Aguilar, Y.; Araiza, J.; \& Melis, Ch. (2006). Nueva evidencia a favor del tercer periodo evolutivo del español: el orden de las palabras. Signos Lingüísticos, 3, 33-67.

Ammon, U. (2004). Standard variety. In U. Ammon, N. Ditma, K. J. Mattheier \& P. Trudgill (Eds.), Sociolinguistics: An international handbook of the science of language and society (pp. 273-283). Berlin-New York: Walter De Gruyter.

Ariza, M. (1994). De la llamada revolución fonológica del Siglo de Oro. In M. Ariza, Sobre fonética histórica del español (pp. 223-257). Madrid: Arco/Libros.

Bello, A. [1847] 1988. Gramática de la lengua castellana destinada al uso de los americanos, con las notas de Rufino José Cuervo. R. Trujillo (Ed.). Madrid: Arco/Libros.

Bybee, J. (2010). Language, usage and cognition. Cambridge: Cambridge University Press.

Cano, R. (coord.). (2004). Historia de la lengua española. Barcelona: Ariel.

- (1988). El español a través de los tiempos. Madrid: Arco/Libros.

Company Company, C. (2012). Historical morphosyntax and grammaticalization. In I. Hualde, A. Olarrea, \& E. Rourke (Eds.), Handbook of Hispanic linguistics (pp. 673-693). London-New York: Blackwell.

(2015). Continuidades y discontinuidades en la periodización sintáctica del español. La evidencia del siglo XVII. In J. M. García Martín (ed.), Actas del VIII Congreso Internacional de Historia de la Lengua Española (pp. 717-734). Frankfurt-Madrid: Vervuert-Iberoamericana.

Elliot, J. (1963). The imperial Spain. London: Prentice.

Eberenz, R. (1991). Castellano antiguo y español moderno. Reflexiones sobre la periodización en la historia de la lengua. Revista de Filología Española, 71(1-2), 79-106.

Gauger, H.-M. (2004). La conciencia lingüística en la Edad de Oro. In R. Cano (coord.), Historia de la lengua española (pp. 681-700). Barcelona: Ariel.

Girón Alconchel, J. L. (2004). Cambios gramaticales en los Siglos de Oro. In R. Cano (coord.), Historia de la lengua española (pp. 859-894). Barcelona: Ariel.

Hatzfeld, H. (1964). Estudios sobre el barroco. Madrid: Gredos.

Haugen, E. (1966). Dialect, language, nation. American Anthropologist, 68, 922-935.

Lapesa, R. [1947] 1981. Historia de la lengua española. Madrid: Gredos.

López Grigera, M. L. (2004). Historia textual: textos literarios (Siglos de Oro). In R. Cano (coord.), Historia de la lengua española (pp. 700-725). Barcelona: Ariel.

Lynch, J. [1965] 2007. Los Austrias, 1598-1700. Barcelona: Crítica. 
Maravall, J. A. (1975). La cultura del Barroco. Análisis de una estructura histórica. Barcelona: Ariel.

Melis, Ch.; \& Alfonso, M. (2012). Topicalización de complementos circunstanciales. Ponencia leída en el VIII Congreso Internacional de Historia de la Lengua Española. Universidad de Cádiz.

Menéndez Pidal, R. [1904] 1940. Manual de gramática histórica española. Madrid: Espasa Calpe.

- (1991). La lengua castellana en el siglo XVII. Madrid: Espasa Calpe.

[1939] 2005. Historia de la lengua española. Madrid: Fundación Menéndez Pidal.

Milroy, J.; \& Milroy, L. (1997). Varieties and variation. In F. Coulmas (Ed.), The Handbook of Sociolinguistics (pp. 47-64). Oxford: Blackwell.

Montaner Frutos, A. (1989). El concepto de oralidad y su aplicación a la literatura de los siglos XVI y XVII. En torno al vol. 7 de Edad de Oro", Criticón, 45, 183-198.

Ruiz Pérez, P. (2010). Historia de la literatura española, 3: El siglo del arte nuevo. 1598-1691. Madrid: Crítica.

Silva Ceceña, R. (2012). Oraciones finales. Estructura y evolución. Tesis de maestría inédita. México: Universidad Nacional Autónoma de México.

Sloman, S. (2005). Causal models. How people think about the world and its alternatives. Oxford-New York: Oxford University Press.

Tejedo-Herrero, F. (2012). Sobre algunas transformaciones sintácticas y la activa evolución del castellano en el siglo XVI. Romance Philology, 66 (2), 423-447.

Thom, R. (1983). Paraboles et catastrophes. Paris: Flammarion. 